\title{
Responses to the Foraging/Predation Risk Trade-Off and Individual Variability in Population-Level Fitness Correlates
}

\author{
Karl M. Polivka ${ }^{1,2}$ \\ ${ }^{1}$ Department of Ecology and Evolution, University of Chicago, 1101 E 57th Street, Chicago IL 60637, USA \\ ${ }^{2}$ Pacific Northwest Research Station, USDA Forest Service, 1133 N. Western Avenue, Wenatchee WA 98801, USA
}

Correspondence should be addressed to Karl M. Polivka, kpolivka@fs.fed.us

Received 8 March 2011; Accepted 4 April 2011

Academic Editor: P.-A Amundsen

Copyright (C) 2011 Karl M. Polivka. This is an open access article distributed under the Creative Commons Attribution License, which permits unrestricted use, distribution, and reproduction in any medium, provided the original work is properly cited.

\begin{abstract}
Foraging under the influence of interspecific interactions such as competition and predation risk can have effects on the energetic reserves of the forager. Measurements of condition in species such as fish are usually correlated with individual fecundity and, hence, fitness. From work in two study systems in which predation risk regulates habitat selection and foraging behavior of benthic fishes I examined whether risk dependence led to reduced variability in fish condition. In field populations of cottid fishes, observed in an estuarine system and in the near-shore habitat of an oligotrophic lake, I found that individuals that experienced higher predation risk showed reduced variability in CI. Estuarine cottids with high food availability and substantial predation risk varied less in CI among individuals than in the associated tidal creek. In the lake, where there is considerable heterogeneity in benthic food resources, a related cottid species showed reduced variation in CI with increasing predation risk from adults. Finally, I examine my previous experiments showing that the estuarine species is limited in its use of high resource availability in estuaries by competition and predation risk. Here I found that variability in individual condition index (CI) was higher when intraspecific and interspecific competition increased and did not increase in the face of predation risk.
\end{abstract}

\section{Introduction}

Research into how animals select habitats in heterogeneous environments has been informed by how the complementary use of safe, relatively unproductive habitats or patches and more productive yet very risky patches influences overall fitness $[1,2]$. By using food and safety from predation risk in a complementary manner, foraging animals benefit from time spent in safety (i.e., in less risky habitats/patches or through vigilance behaviors; e.g., $[1,3]$ ) when the marginal value of food obtained no longer exceeds the cost of predation. Field measurement of the forager's giving up density (GUD) facilitates study of the behavioral optimization of this trade-off (e.g., [1, 2, 4-6]). GUDs are applicable to a suite of predation-avoidance behaviors such as vigilance $[2,7]$ and apprehension $[2,8]$ and represent the marginal value of food in terms of the risk involved in obtaining it (e.g., $[1,3,9,10]$ and reviewed in [11]).

A forager's present condition (e.g., $[4,12-14]$ ) and the density-dependent distribution of predators [15] affect the amount of risk taken to obtain food, leading to variation in that condition through time (e.g., $[12,16])$, in turn affecting subsequent foraging decisions [17-21]. One prediction of state-dependent foraging is the "asset-protection principle" [22]; specifically, foragers in a good state (as an indicator of high potential future fitness) assume fewer risks and occupy a safer, but less productive patch where condition might decline due to limited foraging. Individuals in a poor state often must take risks to obtain energy for future reproduction, some of which will likely succumb to predation mortality and be removed from the population. One predicted observation is that fitness-related traits such as growth, condition, or survivorship will vary less among individuals foraging under high predation risk compared with individuals foraging under lower risk (Figure 1) [23].

Vigilance or apprehension as complementary behaviors to foraging might lead to reduced variation in condition as predicted above when they vary with the state of each forager $[24,25]$. However, relatively few theoretical or empirical studies address the specific prediction about the stabilization 


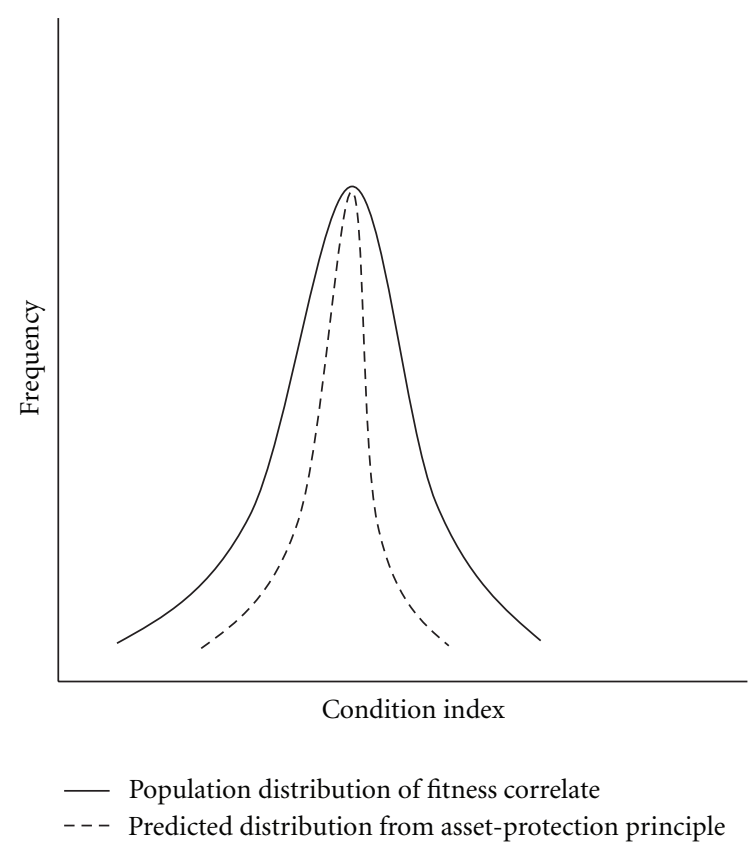

FIGURE 1: Hypothetical frequency distribution of a trait correlated with fitness, such as a condition index, and predicted behaviors for individuals in good condition or poor condition according to the asset protection principle [22] in the presence of a strong foraging and predation risk trade-off. Dashed line shows the reduction in variability for the new trait distribution expected to result from foragers behaving according to the principle.

of state/condition-related parameters among individuals in a population (e.g., $[23,26])$ as a consequence of foraging and predation risk trade-offs in different habitats. Nevertheless, if foraging behavior shows trade-offs consistent with the marginal value theorem, one prediction from dynamic models is fairly constant regulation of condition-related parameters such as individual mass [27]. Often this work requires the use of condition measurements in a retrospective manner, and here I examine field and experimental data for patterns that indicate the possibility of state regulation predicted by [22].

Quantification of patch use and foraging costs using GUDs is tractable for benthic fishes, especially within the family Cottidae [9, 28, 29]. Cottids primarily consume benthic macroinvertebrates whose density at small patches can be measured in context of consumption by fish, correcting for renewal by immigration from other patches. The behavior of cottids is much simpler than that of mammals in the examples cited above; rather than select between a foraging patch and a refuge, cottids remain cryptic and inactive which is analogous to vigilance because there is no intake of energy by foraging. Furthermore, the intensity of foraging decreases with increasing predation risk as measured by using GUDs [9, 28]; thus foraging cottids appear to trade foraging opportunities for vigilance from predation. Here, I use condition data obtained during studies of cottids in two different study systems to examine whether a strong food and safety trade-off is correlated with reduced condition variability, a result previously observed for one cottid species in one of the study systems [28].

In an estuarine/tidal creek study system, predationdependent foraging can affect the variability of a condition index commonly used in fisheries biology [28]. In the estuary, food resources are abundant such that, at the patch scale, the behavioral alternatives for fish are foraging or vigilance $[9,28]$. Short-term experiments showed the effects of predators $[9,28]$ and competitors [30] on growth and GUDs in estuarine individuals; thus the opportunity exists to examine these data for effects on variability in condition. Field-based experimental manipulations require the assumption that the behavior being manipulated is the substitution of vigilance for foraging because small-scale experiments do not offer the opportunity to establish two distinct habitat types for selection by foragers. Given the foraging ecology of cottids, this is a valid assumption and these experiments have proven tractable for the measurement of GUDs [9] and condition variation [28]. A set of experiments dealing with foraging in the presence or absence of predation risk [9] yielded growth rates from which I calculate variability among individuals in replicate field enclosures. I hypothesized that I would observe lower variability in growth in experimental treatments where predation risk was high compared with those where it was low. Likewise, both intraspecific and interspecific competition have been shown to affect variability in state/condition-related parameters [31, 32], often increasing it [33]. Earlier data on the effects of competition between two cottid species [30] enabled me to test the prediction that increased competition would increase variation in condition-related parameters such as growth.

Long-term census data, in which state parameters are measured for individuals, can also provide correlative indications that different levels of predation risk among habitat types affect variability in condition. Using censuses of cottids, I hypothesized that, on average, fish in relatively safe, unproductive patches in the tidal creek would show greater variability in condition than individuals in the estuary where the foraging and predation risk trade-off has been shown to be high $[9,28]$. Separately, I compiled census data from sampling in near-shore microhabitat patches in a lake where a concurrent study found that habitat selection in an ecologically similar cottid is strongly influenced by predation risk (unpublished data), but only broad patterns in condition could be examined because manipulative experiments were not tractable. I hypothesized that in near-shore microhabitats where predation risk was high, I would observe reduced variability in condition as a result of a foraging versus vigilance trade-off, relative to low-risk habitats or experimental treatments.

\section{Study Systems}

Estuarine Cottids. Many fishes (e.g., [28, 30, 34-36] and invertebrates [37] use highly productive estuaries opportunistically to exploit resource availability often as juveniles. Smaller estuarine-opportunist fishes are particularly at risk of predation (e.g., [28, 38-40]), and risk for estuarineopportunist fishes can be greater in estuaries than in stream 
habitats [9]. The coastrange sculpin, Cottus aleuticus, is found in coastal northwestern North America [41] and persists in coastal tidal creeks upstream of the mixohaline zone, but uses estuaries opportunistically [30]. Laboratory experiments showed that this species varies its foraging effort according to short-term fluctuations in energetic reserves [42]. Field experiments in a tidal creek estuary at the Big Beef Creek Research Station in western Washington State, USA (full description in [30]), showed that individuals encounter abundant prey resources in the estuary at the risk of predation by a marine cottid [9], Leptocottus armatus, and further limitation by exploitative competition with $C$. asper [30].

Lake Cottids. Cottus asper, encountered as part of the estuarine assemblage above, is also found in shallow, nearshore areas of lakes that drain out to coastal streams or their tributaries. In Lake Wenatchee, a mid-elevation $(800 \mathrm{~m})$, oligotrophic lake on the eastern slope of the Cascade Mountains, juveniles and adults utilize the littoral zone for foraging at night, but move off-shore during the day. In the near-shore benthos, there is high spatial and temporal heterogeneity in the availability of macroinvertebrate prey; however, the ability of fish to track the quantity of food resources is strongly limited by predation risk from larger conspecifics (unpublished data). Heterogeneity in predation risk facilitated the observation of microhabitat-scale condition variability from month to month during two study seasons.

\section{Methods}

3.1. Short-Term Response of State Variables to Competition and Predation. In my test of the effects of intraspecific competition on growth in both estuarine and stream habitats [30], I used six replicated field enclosures $\left(0.38 \mathrm{~m}^{2}\right.$ benthic area; see [30] for details), stocked at the ambient density for each habitat as calculated from census data in the stream and estuary (1-2 fish per enclosure in the stream, 3-4 in the estuary); six more replicates also contained twice the ambient density. Previous work [30] showed that differences in invertebrate density between habitats (estuary versus stream) over a 4-week period were correlated with differences in both fish density and growth in experimental enclosures among habitats. Intraspecific competition as a result of doubling the density significantly reduced growth in the stream, and, although growth was reduced by intraspecific competition in the estuary, the results suggested that fish were not food limited at that density [30]. Here, I calculated the coefficient of variation $(\mathrm{CV}=\sigma / \mu)$ of the mean growth rate in standard length (SL) and mass for whole enclosures and compared them across treatments to show the extent to which intraspecific competition results in differences in short-term regulation of variation in state-related parameters.

Interspecific competition and predation experiments were conducted in the estuarine habitat only because they were designed to isolate, as much as possible, the effects of species interactions that limit the ability of $C$. aleuticus to exploit estuarine resources. Each experiment consisted of six control replicates of C. aleuticus (32-38 mm SL) at ambient density and six at double density in enclosures as described above. In the interspecific competition experiment, I established a third treatment with six enclosures containing $C$. aleuticus in an additive treatment with competitor $C$. asper such that the interspecific competition treatment contained the same number and biomass of fish as the intraspecific competition treatment. For the predation experiment, the three treatments were similar except that the third contained C. aleuticus with a single, larger L. armatus so that, again, the total biomass in the predation risk treatment was equal to the biomass in the intraspecific competition treatment. The enclosures limited the alternative behaviors to foraging versus vigilance, which is a realistic characterization given that this species and others in the study system are cryptically colored [41] and can use substrate matching to augment crypsis [28]. In each experiment, I again calculated the mean growth rate for each enclosure in the earlier studies $[9,30]$, which I used to compare the CV in growth rate in both mass and standard length (SL) over a 4 -week period. Due to the reduction in survivorship caused by $L$. armatus reported in [9], the CV in growth across replicates was calculated based on the four enclosures where at least one fish remained.

\subsection{Is Variability in Condition Reduced in High-Risk Habitats?} In addition to short-term responses of condition-related parameters in experiments, I examined long-term census data, taken over several sampling years, for differences in the amount of state variation (sensu [28]) among individual C. aleuticus in high-risk estuarine versus low-risk stream habitats. I used the Fulton index as the condition index (CI) which is defined as mass/length ${ }^{3} * 10^{6}$, where the exponent (3.0) was determined for this species by analysis of covariance on a population sample [30] and length = standard length (SL). From summer censuses of fish conducted monthly (May-September) as part of ongoing research between 1998-2002 and from additional censuses 2003-2005, I calculated the CI for all C. aleuticus individuals in each year for which I had measured both SL $(\mathrm{mm})$ and mass $(\mathrm{g})$ in both the stream and the estuary. I pooled the size classes from these censuses because ANCOVA indicated no effect of size on mean CI with sample year as a covariate (unpublished data). In 2001 and 2003, census data were limited to length data only; thus, those years were excluded. I compared the mean CI across years and habitats with a two-way ANOVA in order to examine the habitat $x$ year interaction where a significant term would indicate differences between the estuary and stream in how the mean CI changed over time, that is, was one mean more variable than the other.

In Lake Wenatchee, I examined data collected during monthly sampling of fish and on their invertebrate prey abundance in near-shore benthos from June to October 2004 and bimonthly (March-September) in 2005 at 16 different sampling sites ( $N=9$ sampling events). Fish were captured by seine, and measurements of length and mass were obtained in the field prior to releasing fish to the location of capture. There is considerable spatial and temporal variation 
in juvenile C. asper density, and a concurrent study has found that this is most strongly associated with predation risk from conspecifics (unpublished data). Each sampling occasion at each site and habitat type represented an independent combination of predation risk and potential productivity that could interact to influence individual condition, resulting in $N=138$ samples. Cottus asper adults are predatory on juveniles [43], and I considered "at risk" individuals to be those $<45 \mathrm{~mm}$ and predatory individuals were those $>65 \mathrm{~mm}$ SL (cf. [43]).

Predation risk varied at each site and sampling occasion, and other variables did not influence habitat selection (unpublished data); thus, I estimated the relative risk in each patch over time and analyzed its effect on the CV in condition index. After eliminating samples with zero or one individual $<45 \mathrm{~mm}$, for which the CV could not be calculated, I was unable to include time as a factor in a multifactor analysis of variance due to an unbalanced design. Thus, I performed a repeated measures analysis of variance (ANOVA) on the CVs for all sites across each sampling occasion. To evaluate the effect of predation risk on the CV, I defined risk for each sample by determining the ratio of $C$. asper $>65$ to the number of individuals $<45 \mathrm{~mm}$ observed to be susceptible to predation risk ("high" if predator : susceptible $>0.30$ or "low" if predator: susceptible <0.30). I compared arcsin squareroot transformed coefficients of variation in CI (CVCI) with a one-way ANOVA to estimate the influence of high or low predation risk. Because changes in the mean can influence the coefficient of variation without any real changes in the standard deviation, I also performed a regression analysis of $\mathrm{CV}$ on the mean, using each site and sampling location $(N=139)$ to determine whether any relationship existed between mean CI and CVCI.

\section{Results}

4.1. Short-Term Response of State Variables to Competition and Predation. Differences in the coefficient of variation $(\mathrm{CV})$ in growth were apparent across estuarine and stream habitats and across treatments that manipulated intraspecific competition (Table 1). Variation in growth was 1.3-1.4 (growth in SL) and 1.4-2.2 (growth in mass) times higher under intraspecific competition compared with ambient density treatments in each habitat and was also 1.5-1.7 (SL) and 2.13.2 (mass) times higher in the stream than in the estuary, for each treatment (Table 1). Because the CV was calculated based on the mean growth for each replicate, no further statistical analysis was possible. The standard deviations in each treatment category for each growth response were very similar (Table 1) reflecting the wider distribution of growth rates around a smaller mean.

In the two estuarine experiments where interspecific competition and predation risk were manipulated, interspecific competition increased the CV two- to fourfold, especially for growth in mass where the CV exceeded 1.0 (Table 2(a)). Predation risk from L. armatus resulted in no difference in CV in growth compared with fish at the ambient density and no predation (with the exception of a low CV for growth in SL) or fish in intraspecific competition ( $C$.
TABLE 1: Mean, standard deviation, and coefficient of variation (CV; presented as a proportion) in individual growth rate of C. aleuticus measured in experimental enclosures as change in standard length (SL) or mass. The experiment compared the effects of intraspecific competition (double density) on growth with individuals enclosed at ambient density [30], in estuarine (a) or stream (b) habitats. The $\mathrm{CV}$ was calculated across all replicates $(N=6)$ for each habitat $\mathrm{x}$ treatment block combined.

(a) Estuarine growth

\begin{tabular}{lcccc}
\hline & \multicolumn{3}{c}{ Ambient density } & \multicolumn{3}{c}{ Intraspecific competition } \\
& Mean $( \pm \mathrm{SD})$ & $\mathrm{CV}$ & Mean $( \pm \mathrm{SD})$ & $\mathrm{CV}$ \\
\hline $\begin{array}{l}\text { SL } \\
(\mathrm{mm} / \mathrm{month})\end{array}$ & $6.08(2.25)^{*}$ & 0.37 & $5.08(2.37)^{*}$ & 0.47 \\
$\begin{array}{l}\text { Mass } \\
\text { (g/month) }\end{array}$ & $0.66(0.31)^{*}$ & 0.48 & $0.43(0.30)^{*}$ & 0.69 \\
\hline * Mean growth previously reported in Polivka [30].
\end{tabular}

(b) Stream growth

\begin{tabular}{lcccc}
\hline & \multicolumn{3}{c}{ Ambient density } & \multicolumn{2}{c}{ Intraspecific competition } \\
& Mean $( \pm \mathrm{SD})$ & $\mathrm{CV}$ & Mean $( \pm \mathrm{SD})$ & $\mathrm{CV}$ \\
\hline $\begin{array}{l}\text { SL } \\
(\mathrm{mm} / \text { month })\end{array}$ & $4.38(2.34)^{*}$ & 0.54 & $3.00(2.33)^{*}$ & 0.78 \\
$\begin{array}{l}\text { Mass } \\
\text { (g/month) }\end{array}$ & $0.28(0.27)^{*}$ & 0.99 & $0.11(0.25)^{*}$ & 2.22 \\
\hline *
\end{tabular}

* Mean growth previously reported in Polivka [30].

TABLE 2: Mean, standard deviation, and coefficient of variation (CV) in growth rate for C. aleuticus in experimental arenas stocked to compare the ambient density of fish in the estuary (control) with (a) double the observed density (intraspecific competition) and interspecific competition from Cottus asper and (b) intraspecific competition and predation risk from Leptocottus armatus $(N=6$ enclosures, all treatments).

(a) Competition

\begin{tabular}{lcccc}
\hline & \multicolumn{2}{c}{ SL $(\mathrm{mm} / \mathrm{month})$} & \multicolumn{2}{c}{ Mass $(\mathrm{g} / \mathrm{month})$} \\
& Mean $( \pm \mathrm{SD})$ & $\mathrm{CV}$ & Mean $( \pm \mathrm{SD})$ & $\mathrm{CV}$ \\
\hline $\begin{array}{l}\text { Control } \\
\begin{array}{l}\text { Intraspecific } \\
\text { competition }\end{array}\end{array}$ & $5.45(0.86)^{*}$ & 0.16 & $0.34(0.11)^{*}$ & 0.31 \\
$\begin{array}{l}\text { Interspecific } \\
\text { competition }\end{array}$ & $2.38(0.68)^{*}$ & 0.20 & $0.28(0.10)^{*}$ & 0.35 \\
\hline
\end{tabular}

* Mean growth previously reported in Polivka [30].

(b) Predation risk

\begin{tabular}{lcccc}
\hline & \multicolumn{2}{c}{ SL $(\mathrm{mm} / \mathrm{month})$} & \multicolumn{2}{c}{ Mass $(\mathrm{g} / \mathrm{month})$} \\
& Mean $( \pm \mathrm{SD})$ & $\mathrm{CV}$ & Mean $( \pm \mathrm{SD})$ & $\mathrm{CV}$ \\
\hline Control & $3.85(1.79)^{*}$ & 0.46 & $0.18(0.12)^{*}$ & 0.66 \\
Intraspecific & $2.37(1.77)^{*}$ & 0.72 & $0.13(0.09)^{*}$ & 0.63 \\
competition & & & & \\
Predation risk & $2.93(1.95)^{*}$ & 0.68 & $0.18(0.11)^{*}$ & 0.61 \\
\hline
\end{tabular}

${ }^{*}$ Mean growth previously reported in Polivka [30].

aleuticus) at double the ambient density (Table 2(b)). In all cases, increases in $\mathrm{CV}$ were also associated with decreases in the mean growth for SL or mass. 
TABle 3: Results of a two-way analysis of variance for condition index (CI) of juvenile and adult $C$. aleuticus censused $(N=523)$ across all study years 1998-2005, to compare fluctuations in mean $\mathrm{CI}$ among estuarine and stream habitats.

\begin{tabular}{lcccc}
\hline Factor & df & MS & $F$ & $P$ \\
\hline Habitat & 1 & 0.47 & 8.95 & $.029^{*}$ \\
Year & 5 & 0.42 & 8.41 & $<.001^{*}$ \\
Habitat * year & 5 & 0.33 & 6.39 & $<.001^{*}$ \\
Error & 488 & 0.05 & & \\
\hline
\end{tabular}

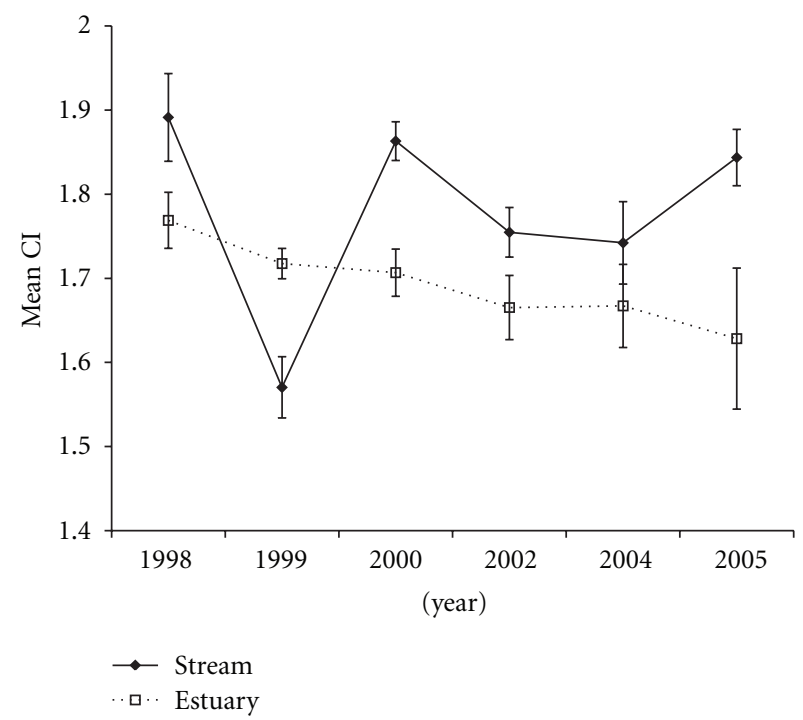

Figure 2: Mean $( \pm$ SE) CI among individuals from census surveys taken in each of the years 1998-2000 in stream and estuarine habitats for C. aleuticus. Mean CI was greater on average in the stream but annual fluctuations in mean CI differed between habitats (two-way ANOVA; see text, Table 2).

4.2. Is Variability in Condition Reduced in High Risk Habitats? Observed size data on juvenile and adult C. aleuticus in the stream indicated wider fluctuations in CI across years compared with those in the estuary. Across all years in the study period, the mean CI for stream populations ranged from 1.57 to 1.88 whereas that for estuarine fish ranged from 1.62 to 1.78 (Figure 2, Table 3). Condition index differed among habitats $\left(\mathrm{F}_{5,488}=8.95, P=.029\right)$, years $\left(\mathrm{F}_{5,488}=\right.$ $8.41, P<.001)$ and, most importantly, showed a significant interaction between habitat and year $\left(\mathrm{F}_{5,488}=6.40, P<.001\right)$, which suggests that condition fluctuated to a greater extent in the stream compared with the estuary (Figure 2).

Capture of $C$. asper in Lake Wenatchee yielded 1289 fish in the "susceptible" size class and 428 in the "predatory" size class, captured in $N=138$ different samples, and found that differences in predation risk resulted in different patterns of variation in individual condition across the population. Repeated measures ANOVA demonstrated that neither habitat $\left(\mathrm{F}_{1,5}=1.01, P=.362\right)$ nor time $\left(\mathrm{F}_{8,40}=\right.$ $1.10, P=.385)$ affected the variation $\mathrm{CI}$ across the sampling period. The CVCI, however, was significantly lower when predation risk was high at the time of sampling (one-way

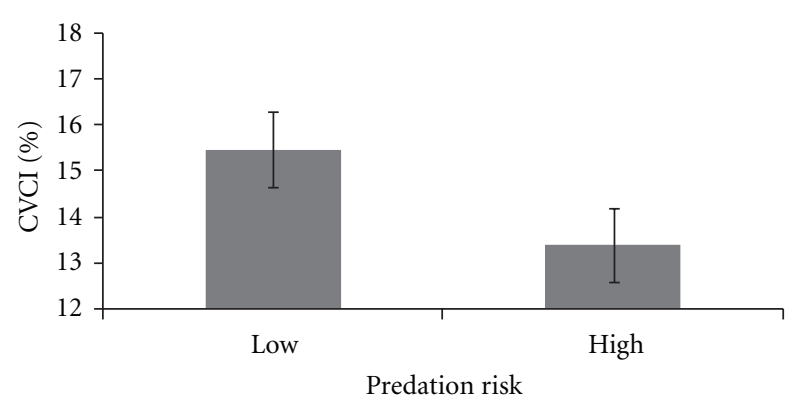

Figure 3: Mean coefficient of variation in condition index (CVCI) for Cottus asper sampled in near-shore microhabitats in the summers of 2004-2005 under varying predation regimes calculated from the ratio of predatory adults $(>65 \mathrm{~mm}$ standard length) to susceptible young-of-the-year ( $<45 \mathrm{~mm}$ standard length). Difference was significant by ANOVA $\left(\mathrm{F}_{1,136}=4.32, P=.040\right.$; data arcsin, square-root transformed prior to analysis).

ANOVA: $\mathrm{F}_{1,136}=4.32, P=.040$; Figure 3 ). Furthermore, there was a positive relationship between the mean CI of susceptible juveniles and the CVCI $\left(\beta=6.74, \mathrm{~F}_{1,136}=4.87\right.$, $P=.029)$ suggesting that the standard deviation at a microhabitat site increased slightly more quickly than the mean.

\section{Discussion}

Habitats that differ in productivity and safety from predation risk offer foragers the opportunity to maximize fitness by complementary use of foraging and predator avoidance [4, 11] and possibly to regulate variation in state parameters $[22,23]$. With predation-sensitive foraging, a forager's state changes over time, and improved or reduced condition will affect the decision at the next step (e.g., [12, 20, 21]). Taking risks to offset depleted reserves exposes foragers in poor condition to predation $[8,23,44]$. Predation risk alters the foraging behavior of benthic cottids [9, 28], and here I predicted that increasing risk would lead to narrower regulation of condition among individuals. If individuals allocate the risks of foraging relative to available resources and current condition, the opportunity to regulate condition more narrowly follows from the asset-protection principle (Figure 1). Furthermore, if reproductive output depends on condition at the end of a period of foraging and growth in a risky habitat, a forager may attempt to maintain a relatively constant state at nonreproductive times and only increase foraging effort during time intervals immediately prior to the breeding season [22]. Sculpins foraging under varying levels of predation risk in both estuarine/tidal creek and near-shore lake habitats show preliminary evidence of state regulation indicating that this behavioral mechanism contributes to observed patterns of habitat selection in each study system.

A basic estimate of fish condition from both census data and experiments revealed that variability among individuals might be associated with differences among habitats in predation risk. Because estuarine cottids in my study system showed evidence of foraging in a state-dependent manner [42], I used an approach similar to that of Sinclair and 
Arcese [23] to examine variation among individuals in the stream and estuary populations. In both my study and theirs, habitats had sufficient productivity to not be food-limiting to foragers, which suggested that foraging would be sensitive to the predation risk involved. A key difference, however, is that they did not look specifically at an index of variation in condition index; rather, this was inferred by identifying the condition of the individuals found to have succumbed to predation. Although my study systems did not allow for the recovery of individuals lost to predation, they did allow me to compare condition variability in individuals in habitats with high predation risk to those in low-risk habitats.

\subsection{Short-Term State Variation Associated with Competition} and Predation. In the experimental arenas, the $\mathrm{CV}$ in growth measured under predation risk did not differ from control or intraspecific competition treatments, and in the case of growth in SL the CV in the low density, no predator treatment was the lowest. Nevertheless, the trade-off between high food availability and high predation risk may stabilize variation in growth in the longer term as shown in the field censuses. Although it is unclear why the CV for growth in SL in the low density treatment was lower than that in the other treatments, growth in mass had a similar CV in growth for all treatments suggesting some stabilization. It is possible that the experimental design did not allow for the time frame that may be required to observe an actual reduction in variance under a strong food and vigilance trade-off. More experimentation is required to determine whether the trade-off merely prevents increases in variability or reduces it relative to control conditions at longer time scales.

Intra- and interspecific competition has been shown to affect variability in state/condition-related parameters; for example, the coefficient of variation for height and mass of a plant population can increase with competition [31, 32]. Competition also interacts with inherent growth rates and initial size distributions to increase the coefficient of variation in size among pre-metamorphic amphibians [33]. Thus, it is reasonable to predict that competition might have different effects than predation risk on variation in fitness-correlated parameters. In my estuarine experiment, interspecific competition was associated with increased variation in the growth rate of individuals whereas variation in growth under intraspecific competition was similar to ambient density situations (Table 2). However, intraspecific competition in the first experiment (Table 1) resulted in increased variation in growth rates, which was consistent with findings relative to state variables in other study systems [45]. This ambiguity warrants further investigation. The decrease in mean growth with competition [30] was associated with similar values for the standard deviation between the two treatments. Nevertheless, the standard deviation was a greater percentage of the mean; thus, increased variability in growth rate could be a secondary consequence of the competitive superiority of C. asper over C. aleuticus found previously [30]. Importantly, however, competitive interactions can affect vigilance patterns [46] which, combined with the implications of field observations under predation, motivate future studies of the dynamics of these two species under predation from Leptocottus armatus.

\subsection{Condition Variation under Different Foraging/Predation} Risk Regimes. Predation risk causes the forager to incur a measurable cost to foraging $[2,8,47]$, and previous work in the estuarine study system has shown that this cost is mediated through vigilance behavior, that is, reduction in foraging $[9,28]$. Estuarine C. aleuticus show reduced GUDs in the presence of predators [9]; here I show that it is also likely that this trade-off between vigilance and foraging is a mechanism for reducing variability in staterelated parameters. Fish do not generally benefit from true vigilance behaviors found in mammals such as alarm calls (e.g., [48]), but reduced activity, like that observed in cottids $[9,28,29]$, is typical for many species (e.g., [49]).

The trade-off between foraging opportunities and predation risk is variable in space and time [50] and is usually apparent as more productive habitats or patches become available, but have high associated risks sometimes mediated through reduced foraging, vigilance, or apprehension $[2,24$, 51]. In the estuary at Big Beef Creek, foraging by small cottids is limited by predation risk from larger ones: in the upper intertidal occupied by Cottus aleuticus there is little habitat complexity; vigilance has a measurable cost to foraging [9]. Lower in the intertidal zone, Clinocottus acuticeps can select refuge habitat provided by an intertidal marine alga which enables regulation of variability in growth rates relative to open habitats that lack cover [28]. From the long-term data set on individuals censused in the estuary compared with the less productive stream, higher stability in mean CI across sampling years was evident in the estuary compared with the stream. It is important to note that mean CI was higher in the stream in most years, despite being more variable through time. Although the stream shows lower resource availability [30], it is possible that individuals in better condition are found more frequently there because the stream habitat also lacks large benthic predators like L. armatus. More controlled experiments allowing for the manipulation of state prior to observations of foraging behavior are needed to determine the effect of state regulation on future foraging. In many study systems involving fish, stabilization of populations is often through size-selective predation leading to a smaller range of prey fish sizes (e.g., [52]). My study systems show that nonlethal effects of predation risk may also stabilize long-term condition which can have subsequent effects on the fitness of individuals in the population as predicted by the asset-protection principle [22].

In near-shore microhabitats of Lake Wenatchee, predation risk appears to have much stronger influence over habitat selection than food availability, and mean CI was found to be higher when risk is high (unpublished data). Because of this, the differences in CVCI reported here (Figure 3) might reflect the effect of a lower mean, but with no actual change in standard deviation. However, the increase in CVCI with increasing mean CI shown by regression $(\beta=6.74)$ demonstrates that increases in the mean were associated with even greater increases in the standard deviation [53] and that the observed difference 
among predation regimes was not strictly a mathematical property of the CI; thus predation risk, as defined in this study, is associated with decreased condition variability. Although the repeated sampling at each of the 16 sites can cause pseudoreplication effects, the lack of site or habitat type effects through time in the repeated measures ANOVA suggests independence among samples, and thus, I was able to obtain a broader range of densities of both predatory and susceptible individuals. As shown by the tidal creek estuary system, intraspecific effects due to varying density through time at each site could influence condition variability in the lake system but similar short-term experiments proved to be intractable there (unpublished data).

Individual behavior can have consequences for population-level processes when, for example, the trade-off between foraging and predation risk affects variability in fitness correlates such as individual condition. This study shows that basic information collected during censuses of the abundance of populations can be very informative. For example, if researchers wish to ask questions about the effects of changes in productivity in a particular habitat type or of introduced, removed, or extirpated predators, then comparisons of condition variability across habitats can indicate whether the traits important to population dynamics have been destabilized well before other detrimental changes occur. This link between population and behavioral ecology might be applicable to any system in which the analysis of population dynamics alone fails to identify mechanisms such as predation risk that interact with other resources in important ways. Such application would further benefit from an experimental approach where manipulations are more feasible, to determine whether behavioral data support the patterns identified by census data.

\section{Acknowledgments}

Support for the work at the Big Beef Creek Research Station was provided by a Department of Education GAANN Fellowship and a Sigma Xi Grant-in-Aid of Research to K. M. Polivka while at University of Chicago. Work at Lake Wenatchee was supported by the Pacific Northwest Research Station (USDA Forest Service), Bonneville Power Administration, the Okanogan-Wenatchee National Forest, and Thousand Trails. This study was originally submitted in partial fulfillment of the requirements for a $\mathrm{Ph}$. D. degree in the Department of Ecology and Evolution at the University of Chicago. Ideas for this study and comments on early drafts of the paper were contributed by C. Pfister, J. Brown, B. Chernoff, M. Leibold, and T. Wootton. Comments on later drafts were provided by B. Kotler, A. Rosenberger, R. Woodsmith, and K. Sirianni. This work was conducted under the administration of the University of Washington Institutional Animal Care and Use Committee (Protocol no. 3286-06). G. George and K. Schmitt provided the use of space and facilities at the station. Field assistance at Lake Wenatchee and in 2004-2005 samples at Big Beef Creek was provided by K. Logan, S. Eichler, B. Eichler, and E. Eichler. Additional assistance at Lake Wenatchee was provided by J. Kill, H. Bushy, J. Bridge, and J. Layman.

\section{References}

[1] J. S. Brown, "Patch use under predation risk. I. Models and predictions," Annales Zoologici Fennica, vol. 29, no. 4, pp. 301309, 1992.

[2] J. S. Brown, "Vigilance, patch use and habitat selection: foraging under predation risk," Evolutionary Ecology Research, vol. 1, no. 1, pp. 49-71, 1999.

[3] E. L. Charnov, "Optimal foraging, the marginal value theorem," Theoretical Population Biology, vol. 9, no. 2, pp. 129-136, 1976.

[4] S. L. Lima and L. M. Dill, "Behavioral decisions made under the risk of predation: a review and prospectus," Canadian Journal of Zoology, vol. 68, no. 4, pp. 619-640, 1990.

[5] J. F. Gilliam and D. F. Fraser, "Habitat selection under predation hazard: test of a model with foraging minnows," Ecology, vol. 68, no. 6, pp. 1856-1862, 1987.

[6] J. S. Brown, "Patch use as an indicator of habitat preference, predation risk, and competition," Behavioral Ecology and Sociobiology, vol. 22, no. 1, pp. 37-47, 1988.

[7] J. S. Brown, B. P. Kotler, and A. Bouskila, "The ecology of fear and the foraging game between owls and gerbils," Annales Zoologica Fennica, vol. 38, pp. 71-87, 2001.

[8] B. P. Kotler, J. S. Brown, and A. Bouskila, "Apprehension and time allocation in gerbils: the effects of predatory risk and energetic state," Ecology, vol. 85, no. 4, pp. 917-922, 2004.

[9] K. M. Polivka, "Use of techniques from foraging theory to quantify the cost of predation for benthic fishes," Transactions of the American Fisheries Society, vol. 136, no. 6, pp. 17781790, 2007.

[10] J. S. Brown, B. P. Kotler, and W. A. Mitchell, "Foraging theory, patch use, and the structure of a Negev Desert granivore community," Ecology, vol. 75, no. 8, pp. 2286-2300, 1994.

[11] J. S. Brown and B. P. Kotler, "Hazardous duty pay and the foraging cost of predation," Ecology Letters, vol. 7, no. 10, pp. 999-1014, 2004.

[12] M. Mangel and C. W. Clark, Dynamic Modeling in Behavioral Ecology, Princeton University Press, New Jersey, NJ, USA, 1988.

[13] J. M. McNamara and A. I. Houston, "The value of fat reserves and the tradeoff between starvation and predation," Acta Biotheoretica, vol. 38, no. 1, pp. 37-61, 1990.

[14] A. I. Houston, J. M. McNamara, and J. M. C. Hutchinson, "General results concerning the trade-off between gaining energy and avoiding predation," Philosophical Transactions or the Royal Society of London B, vol. 341, no. 1298, pp. 375-397, 1993.

[15] D. M. Hugie and L. M. Dill, "Fish and game: a game theoretic approach to habitat selection by predators and prey," Journal of Fish Biology, vol. 45, supplement A, pp. 151-169, 1994.

[16] J. M. McNamara and A. I. Houston, "State-dependent ideal free distributions," Evolutionary Ecology, vol. 4, no. 4, pp. 298311, 1990.

[17] D. Ludwig and L. L. Rowe, "Life-history strategies for energy gain and predator avoidance under time constraints," American Naturalist, vol. 135, no. 5, pp. 686-707, 1990.

[18] L. Rowe and D. Ludwig, "Size and timing of metamorphosis in complex life cycles: time constraints and variation," Ecology, vol. 72, no. 2, pp. 413-427, 1991.

[19] L. L. Oksanen and P. Lundberg, "Optimization of reproductive effort and foraging time in mammals: the influence of resource level and predation risk," Evolutionary Ecology, vol. 9, no. 1, pp. 45-56, 1995. 
[20] S. F. Railsback, B. C. Harvey, R. H. Lamberson, D. E. Lee, N. J. Claasen, and S. Yoshisara, "Population-level analysis and validation of an individual-based cutthroat trout model," Natural Resource Modeling, vol. 15, pp. 83-110, 2002.

[21] S. F. Railsback and B. C. Harvey, "Analysis of habitat-selection rules using an individual-based model," Ecology, vol. 83, no. 7, pp. 1817-1830, 2002.

[22] C. W. Clark, "Antipredator behavior and the asset-protection principle," Behavioral Ecology, vol. 5, no. 2, pp. 159-170, 1994.

[23] A. R. E. Sinclair and P. Arcese, "Population consequences of predation-sensitive foraging: the Serengeti wildebeest," Ecology, vol. 76, no. 3, pp. 882-891, 1995.

[24] B. P. Kotler, J. S. Brown, S. Mukherjee, O. Berger-Tal, and A. Bouskila, "Moonlight avoidance in gerbils reveals a sophisticated interplay among time allocation, vigilance and statedependent foraging," Proceedings of the the Royal Society B, vol. 277, pp. 1469-1474, 2010.

[25] S. R. X. Dall, B. P. Kotler, and A. Bouskila, "Attention, apprehension, and gerbils searching in patches," Annales Zoologici Fennica, vol. 38, no. 1, pp. 15-23, 2001.

[26] E. Sirot and C. Bernstein, "Time sharing between host searching and food searching in parasitoids: state-dependent optimal strategies," Behavioral Ecology, vol. 7, no. 2, pp. 189194, 1996.

[27] P. Nonacs, "State dependent behavior and the marginal value theorem," Behavioral Ecology, vol. 12, no. 1, pp. 71-83, 2001.

[28] K. M. Alofs and K. M. Polivka, "Microhabitat-scale influences of resources and refuge on habitat selection by an estuarineopportunist fish," Marine Ecology Progress Series, vol. 271, pp. 297-306, 2004.

[29] J. T. Petty and G. D. Grossman, "Giving-up densities and ideal pre-emptive patch use in a predatory benthic stream fish," Freshwater Biology, vol. 55, no. 4, pp. 780-794, 2010.

[30] K. M. Polivka, "Resource-matching across habitats is limited by competition at patch scales in an estuarine-opportunist fish," Canadian Journal of Fisheries and Aquatic Sciences, vol. 62, no. 4, pp. 913-924, 2005.

[31] J. Weiner and S. C. Thomas, "Size variability and competition in plant monocultures," Oikos, vol. 47, no. 2, pp. 211-222, 1986.

[32] S. Sugiyama and F. A. Bazzaz, "Plasticity of seed output in response to soil nutrients and density in abutilon theoprhasti: implications for maintenance of genetic variation," Oecologia, vol. 112, no. 1, pp. 35-41, 1997.

[33] H. M. Wilbur and J. P. Collins, "Ecological aspects of amphibian metamorphosis: non-normal distributions of competitive ability reflect selection for facultative metamorphosis," Science, vol. 182, pp. 1305-1314, 1973.

[34] R. T. Kneib, "Patterns in the utilization of the intertidal salt marsh by larvae and juveniles of Fundulus heteroclitus (Linnaeus) and Fundulus luciae (Baird)," Journal of Experimental Marine Biology and Ecology, vol. 83, no. 1, pp. 41-51, 1984.

[35] S. M. Sogard, "Variability in growth rates of juvenile fishes in different estuarine habitats," Marine Ecology Progress Series, vol. 85, no. 1-2, pp. 35-53, 1992.

[36] K. E. Limburg, M. L. Pace, and D. Fischer, "Consumption, selectivity, and use of zooplankton by larval striped bass and white perch in a seasonally pulsed estuary," Transactions of the American Fisheries Society, vol. 126, no. 4, pp. 607-621, 1997.

[37] M. P. Covi and R. T. Kneib, "Intertidal distribution, population dynamics and production of the amphipod Uhlorchestia spartinophila in a Georgia, USA, salt marsh," Marine Biology, vol. 121 , no. 3 , pp. 447-455, 1995.
[38] R. T. Kneib, "Predation risk and use of intertidal habitats by young fishes and shrimp," Ecology, vol. 68, no. 2, pp. 379-386, 1987.

[39] R. T. Kneib, "Growth and mortality in successive cohorts of fish larvae within an estuarine nursery," Marine Ecology Progress Series, vol. 94, no. 2, pp. 115-127, 1993.

[40] L. B. Crowder, D. D. Squires, and J. A. Rice, "Nonadditive effects of terrestrial and aquatic predators on juvenile estuarine fish," Ecology, vol. 78, no. 6, pp. 1796-1804, 1997.

[41] D. S. Lee, C. R. Gilbert, C. H. Hocutt, R. E. Jenkins, D. E. McAllister, and J. R. Stauffer Jr., Atlas of North American Freshwater Fishes, North Carolina Stat Museam of Natural History, Raleigh, NC, USA, 1980.

[42] K. M. Polivka, Foraging theory, habitat selection, and the ecology of a guild of benthic estuarine fishes, Ph.D. Dissertation, University of Chicago Press, Chicago, Ill, USA, 2002.

[43] C. A. Pfister, "Some consequences of size variability in juvenile prickly sculpin, Cottus asper," Environmental Biology of Fishes, vol. 66, no. 4, pp. 383-390, 2003.

[44] W. Cresswell, "Diurnal and seasonal mass variation in blackbirds Turdus merula: consequences for mass-dependent predation risk," Journal of Animal Ecology, vol. 67, no. 1, pp. 78-90, 1998.

[45] B. S. Dezfuli, S. Volponi, I. Beltrami, and R. Poulin, "Intra- and interspecific density-dependent effects on growth in helminth parasites of the cormorant Phalocrocorax carbo sinensis," Parasitology, vol. 124, no. 5, pp. 537-544, 2002.

[46] L. L. Sharpe, A. S. Joustra, and M. I. Cherry, "The presence of an avian co-forager reduces vigilance in a cooperative mammal," Biology Letters, vol. 6, no. 4, pp. 475-477, 2010.

[47] G. Cowlishaw, M. J. Lawes, M. Lightbody, A. Martin, R. Pettifor, and J. M. Rowcliffe, "A simple rule for the costs of vigilance: empirical evidence from a social forager," Proceedings of the Royal Society B: Biological Sciences, vol. 271, no. 1534, pp. 27-33, 2004.

[48] A. Roux, M. I. Cherry, L. Gygax, and M. B. Manser, "Vigilance behavior and fitness consequences: comparing a solitary foraging and an obligate group-foraging mammal," Behavioral Ecology and Sociobiology, vol. 63, no. 8, pp. 1097-1107, 2009.

[49] B. D. Wisenden, J. Karst, J. Miller, S. Miller, and L. Fuselier, "Anti-predator behaviour in response to conspecific chemical alarm cues in an esociform fish, Umbra limi (Kirtland 1840)," Environmental Biology of Fishes, vol. 82, no. 1, pp. 85-92, 2008.

[50] S. L. Lima and P. A. Bednekoff, "Temporal variation in danger drives antipredator behavior: the predation risk allocation hypothesis," American Naturalist, vol. 153, no. 6, pp. 649-659, 1999.

[51] B. P. Kotler, J. S. Brown, S. R. X. Dall, S. Gresser, D. Ganey, and A. Bouskila, "Foraging games between gerbils and their predators: temporal dynamics of resource depletion and apprehension in gerbils," Evoutionary Ecology Research, vol. 4, no. 4, pp. 495-518, 2002.

[52] J. K. Craig, B. J. Burke, L. B. Crowder, and J. A. Rice, "Prey growth and size-dependent predation in juvenile estuarine fishes: experimental and model analyses," Ecology, vol. 87, no. 9, pp. 2366-2377, 2006.

[53] R. R. Sokal and F. J. Rohlf, Biometry, W. H. Freeman, New York, NY, USA, 3rd edition, 1995. 


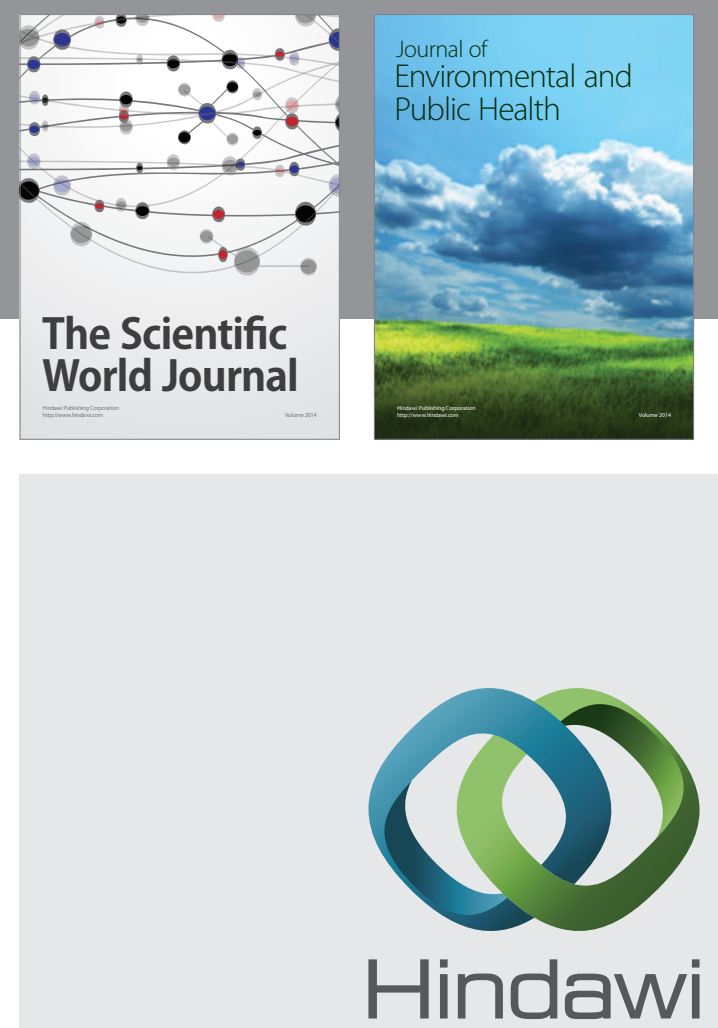

Submit your manuscripts at

http://www.hindawi.com
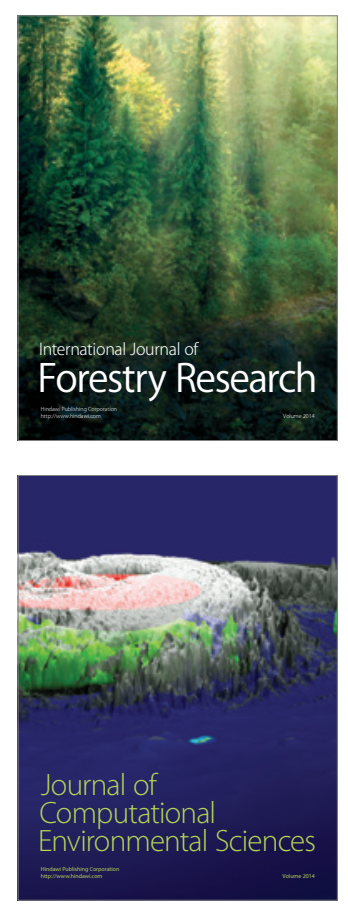
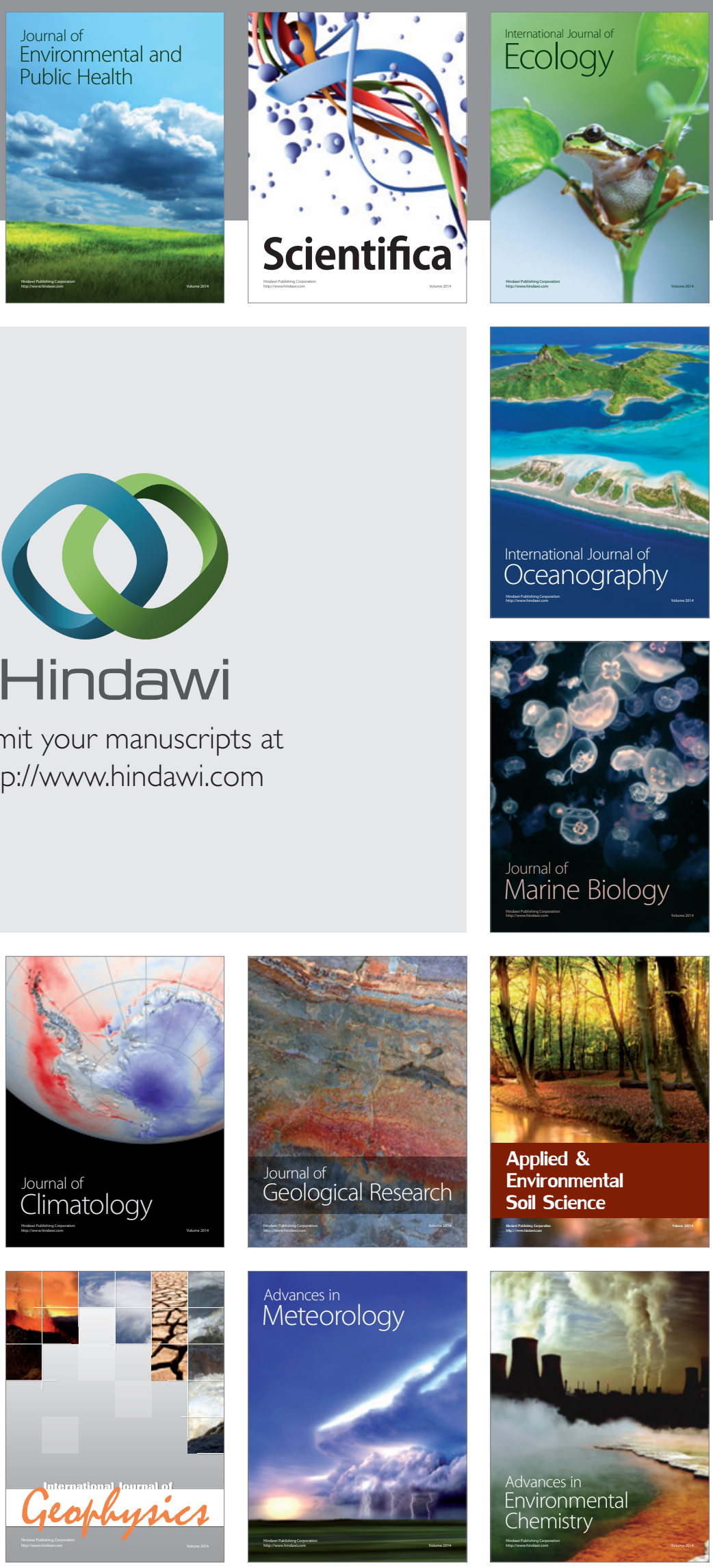